\title{
To tell or not to tell: how children of same-gender parents negotiate their lives at school
}

\section{Carien Lubbe \\ Department of Educational Psychology, University of Pretoria}

Dr Carien Lubbe is a lecturer in the Department of Educational Psychology at the University of Pretoria. Her main research interest focuses on same-gendered (lesbian/gay) families. Other research areas include the exploration of asset-based and positive psychological approaches in Educational Psychology. Carien has a sincere interest in qualitative methodologies, especially narrative research. She is currently involved in the training of psychological counsellors (Honours programme), as well as the supervision of the career psychology component in a Master's programme.

\begin{abstract}
In this article I explore the reported experiences of children growing up in same-gendered families, with a specific focus on their experiences in their respective school settings. In this article the focus is on whether or not the children disclose their family structure, therefore focusing on disclosure and silence. I propose certain factors that might increase the possibility of open disclosure with positive outcomes, as well as investigate the factors that might encourage silence. In this article I argue that schools can be either places of tolerance and acceptance or of intolerance and prejudice. Those two standpoints are not, however, fixed but exist simultaneously in any given school. This article is structured by first offering an overview of how the children perceived different school climates/atmospheres, and is organised around the themes of tolerant and less tolerant school environments. Thereafter the focus is on individual narratives, to illuminate the way in which children in same-gendered families disclose and negotiate their lives in a school system. This discourse concludes with recommendations for schools and further research.
\end{abstract}

Keywords: Same-gendered families, Lesbian/gay families, Disclosure, Negotiate, Tolerance, Narrative research.

\section{Introduction}

What characterises open, fair and non-discriminatory societies? Schools could be an 'ideal' context for ascertaining how far a society has progressed in terms of tolerance and acceptance of diversity. In this article I explore diversity in terms of sexuality - focusing on same-gendered families ${ }^{1}$.

In South Africa, the terms of the new Constitution advocate the rights of gay and lesbian people to establish life partnerships, become eligible to adopt children, keep custody of their own children in divorce proceedings, be able to undertake co-parenting of their created families and, more

\footnotetext{
${ }^{1}$ Same-gendered family refers to a family constituted by two gay/lesbian parents of the same gender (two males or two females), who are involved in an intimate and committed relationship. While gender in this sense refers to the biological sex of the parent, I acknowledge that gender is socially constructed. It is because of the effect of this construction that I refer to such families as same-gender-ed families and not same-gender families. Such families are also widely referred to as lesbian or gay families, or same-sex families. In addition, four of the five couples interviewed disapproved of the word lesbian, therefore I decided to refer to these families as same-gendered families.
} 
recently, to be married (Alexander, 2006; Singh, 1995; Underhill, 2003). In spite of this, real-life attitudes towards gay and lesbian people are not as easy to change, as is the Constitution and resulting legislation (Cameron-Ellis, 1999; Knoesen, 2004; Singh, 1995). Acceptance and understanding that is characterised neither by silence nor by open judgment and condemnation will naturally grow slowly, after decades of persecution and discrimination, because those negative attitudes are deeply embedded in the societal matrix.

The concept of what a family means is continuously being challenged, mainly due to societal factors such as working mothers, adoption, divorce and HIV/AIDS. Family patterns are always in a process of transformation, and household structures are becoming all the more complex (Ziehl, 2001). Eurocentric and patriarchal definitions of the family are slowly being replaced by more inclusive definitions that take into account the role of culture, gender, history, autonomy, religion and sexual orientation (among other factors) in determining family relationships (Knoesen, 2003). Samegendered families form part of a variety of families that co-exist alongside the more traditional two-parent ones. Despite the slow adaptation within society to same-gendered families, changes can be seen over the course of the last decade in particular. As such families become more visible, it becomes imperative that same-gendered families will identify themselves in the school system, bringing a need for awareness and recognition of their diversity (Perlesz, Brown, Lindsay, McNair, De Vaus \& Pitts, 2006).

When focusing on the current education system, it seems that same-gendered families are mainly absent from being represented in the curriculum in schools. I therefore speculate that samegendered families are consequently absent from the consciousness of both teachers and learners, and this maintains the erroneous assumption that all parental couples are heterosexual. The question therefore arises, whether this in turn serves as a justification for same-gendered families to remain closeted and silenced.

Further questions arise when contemplating the notion of same-gendered families in school systems; for example, what are the implications of the increasing number of same-gendered families, and - consequently - children, entering and being in a school system for school educators, school managers/principals, curriculum planners (especially in terms of the learning area Life Orientation), policy developers, teacher-trainers, school counselors/ school psychologists and other school supporting professionals? Are same-gendered families an issue or not within and for schools, the other school children and the children growing up in same-gendered families? What facilitates openness of same-gendered families in schools? What happens to children from same-gendered families in school settings? Are they merely silenced? What factors contribute to the disclosure or non-disclosure of their family structure?

Traditionally, there has been very little written about same-gendered families by and for educators, especially in South Africa, and much can be learnt from what these children have and are experiencing in schools. This article explores the question of disclosure and non-disclosure from the children's perspective, to acquire a glimpse of how South African schools are coping with the process of accommodating same-gendered families. 


\section{Same-gendered families and schools: a research overview}

The earliest research into same-gendered families began due to legal concerns for the welfare of the children and was specifically directed at establishing what influence - if any - the parents' own sexual orientation might have on the child's own gender identity and sexual orientation, personal development and social relations (Bozett, 1987; Golombok \& Tasker, 1996; Hare, 1994; Koepke, Hare \& Moran, 1992; Patterson, 1992, Powers, 1998; Singh, 1995). Most of the available literature on same-gender couples therefore reflects on the findings of research into issues of parenthood and the same-gender couple themselves.

Conversely, research done specifically from the perspective of the children is limited, and most findings are derived from utilising standardised psychometric assessment strategies (Dundas \& Kaufman, 2000; MacCallum \& Golombok, 2004; Patterson, 1992; Tasker, 1999), or from interviews with the parents (Costello, 1997; Golombok \& Tasker, 1996; Patterson, 1992; Tasker \& Golombok, 1997; Vanfraussen, Ponjaert-Kristofferson \& Brewaeys, 2002). Studies that utilize interviews and other forms of data collection with the children have only recently emerged (Dundas \& Kaufman, 2000; Paechter, 2000; Ray \& Gregory, 2001; Tasker, 2002; Van Voorhis \& McClain, 1996; Wind, 1999).

Research studies that investigate school-related topics are sparse and limited (see e.g., Casper, Schulz \& Wickens, 1992; Clarke, Kitzinger \& Potter, 2004; Jeltova \& Fish, 2005; Kroeger, 2006; Lamme \& Lamme, 2002; Ryan \& Martin, 2000; Victor \& Fish, 1995). Even more limited are studies on school-related topics from the perspectives of the children growing up in same-genderedfamilies (see e.g., Ray \& Gregory, 2001). The impetus for this article is to address this void in the literature by focusing specifically on the school experiences of the children from same-gendered families.

The knowledge and values that are socially constructed in educational settings are typically constructed along heterosexual lines and are bound up with the organisation and regulation of the heterosexual family. According to Epstein, O' Flynn and Telford (2002): "myths of happy heterosexuality" abound at every stage of childhood development from the playhouse of the nursery school to the dating games of senior primary and secondary schools. Heterosexual behaviour and language are integrated and imposed to such a degree within the school culture that they have come to constitute a norm that reflects what is perceived as "natural" (p. 272).

Research findings reveal significant challenges that hinder the development of effective relationships between schools and same-gendered families, namely that significant societal bias remains evident in the portrayal of families in school textbooks (Wallis, 2003). Homophobic prejudices or religious beliefs may not provide the atmosphere of acceptance that is needed and many people demonstrate discomfort talking about different sexual orientations due to a lack of information, experience and understanding (Collins, 2006; Ryan \& Martin, 2000). With few exceptions, schools are not required to talk about same-gendered families or to display positive role models or images of these families (Casper, Schultz \& Wickens, 1992; Kroeger, 2006; Victor \& Fish, 1995). Some educators are concerned that the community might feel that they are promoting a gay/lesbian lifestyle, fear that the children will experience gender confusion and generally feel that same-gendered families are inferior (Ryan \& Martin, 2000; Victor \& Fish, 1995). Ray and Gregory (2001) have shown that an inability to cope with the problem of homophobia culminated in creating a school climate of fear, teasing and bullying. 
International research on possible stigmatisation and bullying by peers has revealed that children growing up in same-gendered families are either teased about their mother's relationship or some other aspect of her identity, or else that they themselves are subjected to homophobic bullying (allegations whether true or not about the child's own sexual orientation). It is not unusual for certain children, especially adolescents, to experience persecution because of their membership of such families (Bozett, 1980, 1987, 1989; Golombok, 1999; Tasker \& Golombok, 1997). Ray and Gregory (2001) interviewed 48 primary school children from same-gendered families and found that they reported high levels of bullying, teasing and silencing, leading to feelings of disempowerment, fear and isolation. The negative effects of bullying were amplified when educators provided no support to the victims or even joined in with the homophobic remarks. This is in contrast to other research findings, which suggest that children in same-gendered families are no more likely to experience teasing or bullying than children from any other family (Green, Mandel, Hotvedt, Gray \& Smith, 1986; Hare, 1994; Patterson, 1997). Clarke, Kitzinger and Potter (2004) note that reporting any negative aspect such as bullying or teasing provokes a dilemma for same-gender parents, since claims about homophobic bullying are frequently used to undermine same-gender parents.

The scarcity of positive images and the abundance of negative stereotypes, as well as the invisibility of same-gendered families in institutions such as schools, all combine to create a sense of difference, uniqueness and secrecy (Bernstein \& Reimann, 2001; Kumashiro, 2003; Wright, 2001). Tasker and Golombok (1997) note that a major challenge for every child is the integration of their family experience with the expectations and values of the wider society outside their home. Although this is a universal challenge, integration is more difficult to achieve when a family's divergence from the prevailing norms within the wider social group is greater than average, as is the case with same-gendered families. Those children also tended to experience a community's disapproval of their parents' relationship as a disapproval of themselves. The sexuality of a gay and lesbian person (the emphasis here being on a parent's sexuality) becomes associated with a feeling of vulnerability (Hancock, 2000).

I assume that children growing up in same-gendered families are aware of the discrimination and stigmatisation aimed at their family structure, evident in some parts of society. Therefore, for most children growing up in same-gendered families, communicating their family structure to friends remains an issue, especially during school years. Gottman (1989) states that children feel pressured to exercise caution in disclosing information about their parents' lifestyle, and fear not only for themselves but for their parents as well (in matters such as, for example, custody or job security). Because they wonder how their friends or classmates might react, they constantly face the dilemma of having to make choices about whom it might be safe to tell and whom it would not be safe to tell.

The exploration of disclosure (to tell or not to tell) in this article is informed by Bozett's social control strategies (Bozett, 1987). He researched the children of gay fathers and identified three social control strategies that children under such circumstances have used to manage their public image. These are specific behaviours that those children employ so that others will perceive them as they want to be perceived.

The first social control strategy is boundary control, which entails the control of the parent's (father's) behaviour (for example by not bringing a co-parent - the non-biological parent - to the 
school); or control of their own behaviour (e.g. not inviting the parent or co-parent to school functions). The second social control strategy is nondisclosure, where they will avoid telling others that their parents are gay or lesbian. Nondisclosure may take forms such as referring to the coparent as an "uncle" or a "housemate", or hiding artifacts such as gay/ lesbian newspapers or magazines when friends visit. The third social control strategy is disclosure. Telling others is a highly selective process, and the children display an immense sensitivity about whom they feel it might be safe to tell.

To summarise, children growing up in same-gendered families are simultaneously members of gay/ lesbian and heterosexual ("straight") communities. Little is known about the ways in which children in same-gendered families function within predominantly heterosexual communities, what makes such functioning possible, and what makes it easy or difficult to manage. What this alludes to is that disclosure becomes an important aspect in the lives of children in same-gendered families, even if it is only a once-off disclosure. This was a driving issue of the broader research project that I conducted, that is, to explore the processes of negotiation between individual children and those members of society with whom these children come into contact, the factors that these children use in their negotiations, and the specific behaviours that these children engage in to encourage or prevent particular situations. The negotiation performed by the children of samegender parents does not mean that they are attempting to accept the dominant discourse of society in an uncritical or unthinking way. It implies the acceptance of an equality of status of both heterosexual and homosexual discourses, a position from which they can become capable of reconciling these two worlds. (Negotiation in this context describes the process of how the children who were the participants confer with others in the transactions between themselves and their peers, close friends and significant others.)

The focus of this article is to explore and discuss these disclosure and negotiation processes specifically in relation to the school experiences of children growing up in same-gendered families, and - in line with the specific methodology used - the ethnographic material that is used to spotlight the voices of such children.

\section{Research design}

I chose to apply narrative inquiry for this research study, as this design aims to understand and represent experiences through the stories that individuals live and tell (Creswell, 2002). The narrative inquirer tells and retells, lives and relives, presents and re-presents the stories of people's lives, as an individual and within a group context, to answer questions on meaning, experience and social significance (Clandinin \& Connelly, 2000). It was my aim to understand the experiences of children growing up in families with same-gender parents; how they think and feel about their lives in relation to the heteronormative image of family life that society constantly projects.

The social constructionist paradigmatic perspective guides the research, as interpretations cannot be disentangled from the social context in which they arise. I believe that the experiences of children growing up in same-gendered families reveal how they co-construct their social reality, and that this reality is itself socially constructed and situated within a specific social, historical and political context (Bevan \& Bevan, 1999; Terre Blanche \& Durrheim, 1999). 
To select the participants I applied the technique of snowball sampling, as same-gendered families can be regarded as a sensitive subject in South Africa. Eight children, from five families, became my research participants - four boys and four girls - whose ages ranged between 9 and 19 years. Two of those children would be regarded as belonging to the racial group referred to as 'Coloured', and the other six to the racial group identifiable as 'White'. Although I used no formal instrument to measure their socio-economic status, one family was from a low-income group, one from a high-income group, and the three others lived in neighbourhoods that one would associate with middle-income. For the purpose of this inquiry I am only reporting on research data from children growing up with lesbian mothers. I intentionally chose female couples as a starting point of my inquiry into same-gendered families. This was based on personal preference, which I can ascribe to my own gender (female) and my preference for a partner of the same gender. Apart from the latter, it is to be remembered research on the subject of gay/lesbian families is limited, and willing participants in this sensitive research area are scarce. Lesbian parents were easier to trace than their male counterparts, although further research is needed to also explore the male (gay) parent situation.

I conducted weekly in-depth interviews with each child and his/her parents (separately or combined was the case with certain families) over a three-to-four month period, utilising supportive data creation methods such as collages, timelines, family stories and artifacts. The unstructured interview was selected as a data-generating tool, as this type of interview offers the participant an opportunity to tell his or her story with minimal interruption from the researcher. Unstructured interviews are most appropriately used in studies where the researcher seeks primarily to discover what is most important to the participants (Morse \& Richards, 2002). The role of the researcher is to listen and let the participant tell her/his story. During follow-up interviews the planned questions I asked were for clarification on past interactions. I made use of unplanned, unanticipated questions, interspersed with questions that probed for clarification. In particular, I initiated the series of interviews by informing the children about the purpose of my research study; I explained I wanted to know from them what it is like living in a same-gendered household - using the appropriate vocabulary as indicated by the parents in my initial contact session (certain families used the phrase "two moms" or "living with another woman", while others the word "partners".) I started by posing a general introductory statement or question; such as: "Tell me about your family." or "What is it like to have two mothers?" After gaining the children's confidence I used an informal conversational style, characterised by general conversation such as talking about the day at school, which gave me the opportunity to probe more gently into specific matters, for example their friendships, whether they had sleepovers and so forth, which usually elicited details of their negotiation between their intimate private lives and the world out there.

The sessions were recorded on magnetic tape and later transcribed. From this transcribed data, narratives were subsequently constructed of each child's reported experiences, to capture the uniqueness, specificity and individuality of each child. Thereafter, Mason's Holistic Analysis (2002) was applied as an interpretive tool to test the data with analytical questions for meaning and significance to then enable me to frame and focus the experiences of children in same-gendered families. Mason (2002) helped me become aware I was searching for the "particular in a context, rather than the common or consistent and for the holistic rather than the cross-sectional" (my emphasis) (p.165). Holistic Analysis implies that the particularity or uniqueness of each individual's story will usually outweigh the search for a more general or common theme in the data. Therefore, 
explanatory or analytical logic, supported by holistic organisation of data, illuminated the experiences of children growing up in same-gendered families and provided possible explanations of the ways in which such children engaged with their world.

That I could organise my data holistically, I reread the raw transcripts and field notes on the collages and timelines several times, to form an overall impression of what each specific child's story was about. My earnest desire was to understand the intricately interwoven parts of each unique story. It was from this emergent overall impression that general patterns in each individual story began to form in my mind. Then, using coloured markers and coloured pens, I worked through the field texts again, identifying narrative threads, tensions and patterns within the field texts of each story. Next I grouped, labeled, organised and sorted the data into themes. For the purpose of this article I focused on the school context as a sub-theme that emerged from the findings.

The criteria of trustworthiness, authenticity, credibility, dependability and reflexivity were employed, typical of qualitative research. Pseudonyms were used throughout the process, and the children and their parents gave informed consent. The utmost care was taken throughout the research process to ensure and maintain a high standard of ethical conduct.

\section{Discussion}

From the experiences reported by the children, I maintain that schools can be places of discrimination and prejudice - silencing minorities and otherness such as same-gendered families - or they can be places of openness, tolerance and even acceptance that serve to enhance disclosure, openness and transparency and authentic relationships in schools. These two standpoints are not definite and exact binaries, but exist simultaneously in any given school, as acceptance or discrimination exists on several levels in any given system.

I will discuss the above standpoints by offering a general overview of how the children perceived different school climates/atmospheres. Thereafter I focus on individual narratives to illustrate whether children growing up in same-gendered families are silenced or not when confronted with teasing or possible incidents of prejudice, and how this influences the way in which they disclose and negotiate their lives within a school system.

\section{Tolerant and less tolerant school environments}

One of the most significant contextual factors common to each child's setting is the school. During the in-depth interviews the children spontaneously shared information about incidents that had happened at their schools. They also appeared to judge their school environments positively or negatively in terms of how accommodating or otherwise the schools were about children who are growing up in same-gendered families.

Let me expand on tolerant versus less tolerant environments by starting off with some of the experiences that Kashni (grade 9) shared. She describes the contrast between her previous school, which was a private school that she attended from Grade 0-7, and the single-gender high school in which she is currently enrolled. Kashni is very sensitive about the different contexts in which she moves; therefore she is quite clear about the difference that a particular kind of school environment can make. 
Most times it's cool... It was really great in Rodcrest College because most of the people there are very open and that was nice. But now, in Festive School, it's a bit more difficult, difficult because many of the people are more conservative.

Kashni defined what openness means to her:

By "open", ... I mean open-minded, tolerant. They are not judgemental about things and they are comfortable with most situations.

The feature that is most crucial for Kashni seems to be whether the people in the school are openminded and enlightened or whether they are conservative in their views. She is very clear about how the different schools influenced her experiences of openness and her acceptance or nonacceptance by others.

Another significant indicator that emerges from the narratives and the interviews, especially as described here by Kashni, is the role that religion plays in creating either tolerance or intolerance.

In Rodcrest College everyone was, like, tolerant and open-minded because there were children from different religions like Islam, and there were also a lot of children from overseas. It is also a private school. It was really nice. But Festive School is more difficult. You know, I also believe in God and I think that I'm spiritual. But Festive School is, like, Christian. You have to be a Christian, pray three times a day and so on, and every morning the school opens with readings from the Bible. I don't mind that kind of thing, but they are, like, heavy about it and they are not tolerant about other religions. They only believe in Christian, um, values, and that's also what makes it so much more difficult there, because the Bible says that it's wrong and everything.

Ryan and Martin (2000) mention religion as an obstacle in creating a tolerant school environment, especially when educators or school administrators have strong views opposing homosexuality. Another prominent example of religious opinions clashing with gay/lesbian parenting is the Surrey School Board's refusal to approve three books portraying gay/lesbian families, due to religious objections from local parents. For six years a heated debate raged until the Supreme Court of Canada handed down a final decision (Collins, 2006). This conflict alludes to the place of religion in education, and schools are traditionally seen as a tool for instilling shared values and a common identity in children from diverse backgrounds. Embracing different values might clearly cause some difficulty for schools.

A further factor (and its complications) that children encounter in schools and that Kashni brought strongly to the fore, is race and racism.

This new school is so much more conservative. They're ****ing conservative and religious. I don't mind all that stuff. But they're racist as well. Even when I'm with them, I sometimes find that I just can't keep quiet about their racism. So, one day, I just said to them: 'When I'm around you, don't say things like that'. But I think that it comes from the parents. Rodcrest College is not racist at all. There are Muslims there, and Jews and Blacks. Schools really make a big difference.

Kashni described the conservative attitudes that she observed in one particular school and how the behaviour of those children influenced her friendships. Ryland (grade 3 ) is also aware of how 
racist factors in his environment make his life a lot less pleasant. The girls and older boys bully him and his friends. His experience of school was characterised by hostility and being bullied and teased, which led me to wonder how he contemplated the possibility of the other children finding out about his family structure.

The Blacks are horrible to me and to my friends. The girls hurt us and tell us to carry their suitcases. The older boys... If you bring something like a tennis ball or anything like that to school, you have to hand it over and give it to them forever.

That's what I said last time. Do you have a problem with my... that I'm a boerkind? And they said, "Yes, because you're White." The other guy, he's the racist in our class.

What the research indicates is that children in same-gendered families experience these visible indicators of difference (such as race) as markers that other people can use to categorise people and make them the objects of prejudice, ridicule and hostility. International research has revealed that visible indicators of difference, such as race and gender, and some not so visible indicators such as culture and sexuality, are used to other certain people, bringing about tension in educational settings (Asher, 2007; Kumashiro, 2000, 2001, 2004). The term other is usually used to refer to those groups that are traditionally marginalized in society, that is, that are other than the norm. Many different groups in society can be and are possibly other-ed, but it mainly refers to groups targeted by racism, classism, sexism, and heterosexism. It is however beyond the scope of this paper to discuss those matters in-depth.

Kashni has possibly obtained her understanding of the difference between how more broad-minded people and those inclined to maintain a more conservative attitude will react to her family structure from her exposure to different schools. Her description of the following event shows the influence that more conservative and/or judgmental remarks had on her openness and willingness to disclose her family structure, as well as on her friendships.

Like, on this one particular day we were all standing at the bus stop, and a guy comes walking past, with his arm around a girl. One could see that they were, like, together. Maybe even married or something like that. Then some of the girls started making spiteful comments and noises. Why? Because the guy was Black and the girl was White. Then I remembered my previous school where we White girls dated Black guys and it didn't matter at all... So I stood there thinking to myself, "If race is such a big issue for you guys, and you can't handle that, then how on earth will I be able to tell you that my parents are gay?" I looked at them... and I thought to myself: "Do I really want to be friends with any of you?" So I pick my friends very carefully, and I don't hang out with children who are like that. If I have to be with them, I just keep quiet and I say nothing.

Kashni seems to know when silence is the best strategy for handling stereotypical perceptions. She would also try, whenever possible, to avoid the company of children who are prejudiced. The above anecdote reflects her sensitivity to other forms of discrimination, such as racist remarks, indicating a sensitive awareness that she displays when she encounters other people, sensing their beliefs and opinions. The intersection between minority categories - such as race - is evident again. 
In contrast to the above, Carl (grade 12) functioned in a school environment that was even tolerant of children who are themselves gay or lesbian. In the following comment he talked about a girl who has come out about her own alternative sexuality:

Everyone knows about Michelle. The girls hug each other. Our school doesn't have a problem.

Luanne (grade 9) also experienced her school context as a more pleasant environment because her peers neither discuss nor comment on the parents and family structures of other children.

No, we don't actually talk about it. Well, we don't talk about that. No one talks about their moms and dads at school. We talk about things like Sewende Laan, music, boys, and new movies.

An alternative explanation might be that Luanne did not want to talk about this at school, and did not want to venture into this topic with me, and therefore answered quickly to avoid exploring the topic. This silence, interestingly enough, contributes to her reported experience of the school as a more tolerant environment. Her observation that the children at her school do not tease those who have divorced parents is perhaps more indicative of her experience that she was enrolled in a more tolerant school.

Children don't tease each other any more about their parents being divorced because just about everybody comes from a divorced family.

According to Kim (19 years old, a student), open-mindedness in the culture of a school permits its learners to live and function in a more carefree way. This open-mindedness also gives learners the opportunity to talk freely to their most intimate friends.

Alene and I used to talk openly about my situation and we did not regard it as weird in any way. In addition, all my friends in $A B C$ were very open-minded about it, and no one thought anything about it

To summarise, tolerant school environments can be characterised by openness and open-mindedness, an acceptance of diversity in terms of race, religion, culture and - by implication - sexual orientation. A tolerant environment contributes to children being able to live in a carefree manner and talk openly about their family life and experiences. Intolerant school environments, on the other hand, can be characterised by judgmental and stereotypical remarks, hostility and bullying, and prejudice towards other religions, race and - probably - sexual orientation as well. Children in same-gendered families are more inclined to be silent about their family lives.

The discussion above highlights that narrative research lends itself to capturing the unique experiences of individuals, and that the data that emerged from this design needs to be analysed and interpreted by exploring each individual context. Therefore, I now set out the way in which the children negotiate their school context, by focusing on their individual experiences, to illuminate the diverse strategies that the children employ.

\section{Individual narratives: negotiating teasing and prejudice}

Most of the children I interviewed had, at one stage or another, encountered a challenging experience that led them to disclose their family structure or to opt for silence - as a protection strategy. In 
the following section I will guide the reader through some of the children's individual accounts to illustrate the different ways in which they negotiate relationships and challenging experiences. I start off by describing contributions by Carl and Kashni as examples of disclosure, brought about by probing or questions from peers. Then Tom and Ryland's contributions of their experiences are discussed as illustrations of the awareness of teasing and how this does or does not lead to disclosure; followed by Luanne's contribution as an example of the invisibility of same-gendered families in a school.

\section{Carl}

Carl faced a challenging incident which shows how the silence about same-gendered families in schools is broken by classmates or peers, who might probe for a disclosure out of curiosity, or sincere interest to know the child better, or even mock, tease, humiliate or embarrass a particular child. Although a few of Carl's friends and his (ex-) girlfriend knew about his domestic situation, Carl was probed in what can be called a forced disclosure in his Grade 11 year. He himself framed the situation as his choice to be out and open about his same-gender parents in a more public way:

It happened last year, at our inauguration as school prefects for the new year. Susan was standing quietly there near the door because she didn't want to be part of the group photograph. Penny, my birth mother, was already standing in the group for the photograph. So I called over to Susan, and said, "Come on, Susan!" So she came over.

After the photos had been taken, a few of us were standing around in a group. Then one of the guys (they were not exactly afraid, but you could see the apprehension in their eyes) asked me "Do you have two mothers, Carl? Or is the one lady your mother and the other lady your step-mother?" Something like that. I can't really remember their exact words now.

So I said, "No, Penny is my mother, and Susan is my dad." When they had recovered from that shock, they said, "But she's a woman!"

And so I said, "So?"

And after that, they never again asked me any other questions about my parents.

Since Carl had not decided before the incident described above whether or not he wanted to disclose this information, he was in a sense forced to decide whether he would tell the "whole truth", or whether he would minimise the disclosure, by framing Susan as "an aunt" or "a friend of his mother". From the way in which Carl described the manner in which the question was put to him, I suspect that there might have been some element of mockery from the other school leaders. But Carl chose not to focus on that. Instead he chose to come out with such honesty and directness in disclosing the special relationship that he has with Susan - whom he regards as his "dad" - that his critics were totally disarmed. The relationship between Susan and Carl transcends all conventional gender boundaries and therefore subverts all conventional constructions of so-called masculine and feminine characteristics. Although it would be both fruitful and rewarding to explore the various ways in which Carl constructs Susan as his dad, a detailed examination is beyond the scope of this article. 
This incident was a way for him to disclose his family constellation in a more public manner and forum than he had ever done before. Although it was a disclosure made under almost irresistible pressure in a public place, Carl responded to the question with a full and valuable admission about Susan's role - though unorthodox - in his life. He could have responded in other ways by, for example, denying the truth or by framing Susan, his co-mother, as an aunt or a friend of his mother. But he chose instead to frame her in a much more powerful and decisive way. He depicted Susan proudly as his dad. By doing so, he demonstrated his own strength of character in a potentially compromising situation. Even though he and his family had been inadvertently exposed, Carl quickly regained control of the situation and made the process of disclosure his own.

The incident described by Carl shows what might happen to children of same-gender parents on an individual level, without the management of the school being aware of it. This indicates the implicit factors present in a school that are underlined by values such as tolerance, acceptance and respect for diversity, which might be more difficult to manage formally.

Sometimes these individual incidents are made more public, and the following experience of Kashni raises questions as to how schools are able to cope with incidents of prejudice and teasing, and how different role-players might prefer such incidents to be handled (e.g. parents of child being teased, parents of other classmates, the educator, the management of the school).

\section{Kashni}

One day these boys were having a go at me and they just went too far and they said things like "You are a lesbian" and "There's something funny about your mother." So I told my mother, and can you believe it? she (it was mom Anriëtte) went to school and she talked first to the principal, and then to my teacher, and then she came and spoke to the whole class. And then she called these boys to the front of the class and said, "Okay, if I ever hear that you have called my daughter a lesbian, I will phone your parents, and then I will lay charges against you for libel. And your parents will have to pay all the legal fees of the court action...". And then she said, "And by the way it's not Kashni who is a lesbian. It's us! If you ever have a problem with that, then you come and tell us." And of course it never was a problem again.

What happened in this incident is in enormous contrast to the way in which Kashni usually controls situations by initially observing the behaviour and reactions of others and then intervening on her own terms. But in this incident I observe first that Kashni was teased and supposedly insulted by remarks that were intended to be derogatory. Significantly, the boys tried to insult Kashni by saying, "You are a lesbian" which Kashni is not. It is interesting to note that, in the ignorance of these boys, merely being a lesbian would constitute an insult. Their undoing then (so graphically portrayed in the passage above) is that they went on to say that there is "something funny" about Kashni's mother. Kashni's mother, Anriëtte, then decided to step in and take control of the situation and, by so doing, remove the responsibility for resolving the situation from her.

Anriëtte's decisively threatening action in the classroom served to create an awareness in the school that same-gender parenting is a responsible and legitimate form of parenting. Her powerful mothering and nurturing action in this case resulted in her regaining control of the situation by shifting the balance of power between the children and the adults, and creating a memorable and significant incident in the history of the school. It also served as an object lesson in the need to 
respect the boundaries between the private and personal sphere and the public sphere of interest and action.

However awkward and embarrassing it must have been for Kashni, it defined the need for respect on the part of the public (represented in this case by the boys and the school) for alternative identities in this case, sexual orientations and same-gendered families. As mentioned before, this also raises the problematic issue of, for example, how the other parents might have felt when this was discussed in class, and how the other seemingly innocent children might have been influenced. This raises the issue for schools of how to handle these other and different families in an attempt to accommodate all diverse aspects.

In some instances, children decide whether or not to disclose when they are confronted not by peers or classmates, but merely by the possibility of teasing. In Tom's case, the mere awareness leads to proactive disclosure with positive results.

\section{Tom}

For Tom, having two mothers meant, is in his own words, "nothing" and "everything is all right". In addition, all his friends and classmates know about his same-gendered family because he disclosed the fact publicly in a class in the year previous to my meeting him (Grade 7). His statement that "half of my friends who come here think it's...You know...That it's suppose to be like that", and that they think "it's fine, it's normal, it's nothing" may also be indicative of his peer group acceptance. The consequences of this public disclosure for Tom are that he experiences acceptance from his peers and that he himself can function in a relaxed and carefree way. For example, he invites friends over without ever thinking or worrying about what they may say or think. Tom's feelings of being content with his family structure are wrapped up in the acceptance of his friends. In his conversations with me, he mentioned that one of his friends "knows that it is no big deal" and that "my friends from school - they are all totally in love with this new arrangement". This indicates the level of spontaneity that exists between Tom and his friends.

According to Tom, his own acceptance happened almost immediately. "When I realised for the first time that my mom was like that, I didn't mind." Perhaps this readiness to accept the situation as it is contributes to the fact that he has no qualms about sharing this information with his friends. What makes Tom's story even more remarkable is that other children he met in similar situations supported his process of reaching this level of acceptance. This suggests that children growing up in same-gendered families are increasingly speaking out. This is important for schools to take cognisance of, as the more same-gendered families emerge and become visible, the more support there is for the children, making it a possibility that tolerance and acceptance might increase throughout an entire school community, and possibly the wider community as well.

Okay, one or two of my friends' dads are also, like, gay as well, and they would tell me about that... They just said that they prefer that to how it used to be before, and they love it... It's, like, their parents are gay, and they were trying to tell me how much easier life is for them because I was thinking that it would all be so much harder. I mean, they are really much happier now than they ever were before.

These words indicate that Tom did go through a period during which he was confused and even though his friends highlighted the positive qualities of living in a same-gendered family, thus 
projecting approval and acceptance of his situation, it took him some time to work out where he stood in relation to his mother's new orientation. Findings from Patterson (1992) and Wright (2001) suggest that having contact with peers in similar situations is frequently supportive. Vanfraussen, Ponjaert-Kristoffersen and Brewaeys (2002) mention that the children in their study felt that children in other same-gendered families would understand their situation better. Ray and Gregory (2001) reported similar findings in that the children in same-gendered families felt more comfortable talking to other children with same-gender parents because they knew that they would not be rejected. For Tom, having friends who were growing up in households that were also run by parents of the same gender, assisted his understanding as he went through the process of coming to terms with what was happening to his mother. These friends played an active part in guiding him on his journey towards acceptance.

However, mere awareness of teasing does sometimes lead to silence, as in the case of brother Ryland.

\section{Ryland}

Ryland's awareness of the possibility of being ridiculed at any time led him to feel dangerously exposed even though his very close friends and his family do not know this. Because he is silent in the public sphere, he lives in fear of being exposed.

That's why I have to keep it a secret, so that people don't tease me... If anyone finds out, I'll run away from school!

Ryland also chose the strategy of silence to protect himself:

No one talks about it because no one knows about it. It's only my family that knows about it, and a few other close people like Anna. It's not wrong! There is nothing wrong with it. We don't tell the children at school and that's how I want to keep it. Now if Danielle (his sister) goes and tells everyone, "I've got two mothers at home", then we will have big problems to deal with.

Some authors argue that the decisive factor is the mere awareness of a perceived stigma or threat of homophobia move than the reality of the stigma itself. This line of research therefore focuses on the fear itself rather than on actual occurrences of homophobia (Bernstein \& Reimann, 2001; Tasker \& Golombok, 1997; Wright, 2001). Others may argue that a perceived threat is as real as an actual threat, and they mention examples such as gay bashings and murders (Greene, 2000; Patterson, 2000), or the fact that same-gendered families remain invisible to schools and other social institutions (Casper, Schultz \& Wickens, 1992; Victor \& Fish, 1995).

\section{Luanne}

Luanne's story is an example of how the invisibility of same-gendered families leads to ignorance; in her case a teacher's seemingly innocent comment probably delivered in good faith that brought her world to a standstill. Nevertheless, in deconstructing the remark made by this teacher, it becomes evident just how prevalent ignorance about sexual orientation and same-gendered families is, and how invisible gayness is in schools. What makes this incident probably more complex is the fact that the notion of religion surfaces as well. 
Luanne remains silent for a moment, and then adds in a quiet voice:

But it is actually wrong to be gay. The Bible says so... I think it's in Romans, chapter 1. A teacher once told us that if you ever do 'it', even once, the Lord will never forgive you because He did not create women for women or men for men. He made man and woman so that they could be together. That's why it is supposed to be a very big sin.

I actually find that very confusing," she continues, "because what if two people really love each other? Look at this new law that parliament has passed, it makes it legal for gay people to marry. And if one takes into account what the church said the other day... Sometimes I just don't understand what's going on.

The statement that the teacher made brought up some difficulties for Luanne. She became torn between accommodating the Bible verses as they are currently translated and interpreted and propagated by some churches, and the very real love that she has for her two mothers. Even though the church that she belongs to (the Dutch Reformed Church of South Africa) had officially altered its position on homosexuality in recent months prior to these interviews, Luanne is confused about where she herself fits into all of this. I am personally aware (in my observations) of how difficult it must have been (and probably still is) for Luanne to interact with her mothers after she had heard and reflected on the teacher's opinions. Luanne might have had an intense struggle to come to terms with it. How in fact does she reconcile these heteronormative statements with her own personal life situation?

From what I could gather from Luanne, she merely continues as best she can with the routines of her daily life: "I just get on with my life." She does not think about her dilemma or mention it to anyone, be they parent, friend, another teacher, a minister or a school counselor. So to whom can she turn for help? Who will offer her a balanced view that will allow her to make up her own mind? Or is the whole subject of homosexuality so charged with negative emotion and antiquated prejudice that it becomes impossible to discuss in a calm, balanced and rational way how homosexuality in all its manifestations has a valuable contribution to make to morality, values, religion, spirituality, love, sex, families, society and caring for our children? Will children simply be left to judge that which they do not understand?

My views apart, this teacher's statement certainly introduced a strong homophobic influence and atmosphere into the school environment. Luanne opted for silence ("No, we don't actually talk about it... We don't talk about it"), and not even she and her intimate friends discussed the incident. She remained silent because she probably experienced the teacher's homophobic remarks as an emotional and intellectual shock, and there was no precedent for discussing parental attitudes in this class. She therefore protected herself by silence. However, her silence in the school and at home is also silencing her parents, as they remain unaware of these incidents. And even if they did know or suspect that homophobic remarks would be made during Luanne's life, how would they manage it or prevent it?

Even though this example might be an isolated event, it serves as an indication of what might happen to children growing up in same-gendered families, and the importance of what a teacher says. In addition, because of the relative novelty and invisibility of same-gendered families in the community, the curricula in schools does not make provision for educating children about same- 
gendered families and alternative sexual orientations. This, in turn, means that teachers can be ignorant about the need in both school and community for taking into account same-gendered families and children from such families. Without officially sanctioned education about samegendered families and alternative sexual orientations, it can be problematic for children from samegendered families to live in a way that integrates the interests of both home and school (Paechter, 2000). An atmosphere hostile to a gay or lesbian sexual orientation can become a reason why a child might prefer to remain "in the closet " about his or her parents' sexual orientation. Even if a teacher does not regard derogatory opinions about homosexuality as an example of stereotypical thinking, she or he exposes children to only one viewpoint out of a multitude of possible viewpoints if she or he does not state "the other side" (or different arguments) specifically and clearly.

To summarise, the different individual circumstances that each child encountered, provide an overview of the individual ways in which children negotiate relationships and, specifically, incidents of teasing, or the mere awareness of the possibility of teasing. What is interesting here is that the children handle these episodes in unique ways. Some negotiate difficult situations directly, which usually leads to positive experiences and outcomes, as in the case of Carl and Tom. Others, like Kashni and Luanne, may feel less competent and so more despondency can be detected, perhaps due to external factors beyond their control.

\section{Recommendations}

A common factor that facilitates disclosure associated with positive outcomes is the presence of an open and accepting school climate, free of harassment, homophobia and discrimination. To create a non-discriminatory educational environment may be, initially, a daunting tack. Children, parents and educators enter the system with their own personal beliefs, which might not always be compatible with the other. However, if prejudices can be acknowledged, addressed and challenged, it could lead to greater understanding and acceptance.

Following the indicators from Kashni's experiences in different school settings, especially the role that religion plays in schools, any school management should be sensitive about how they enforce religious issues, especially those religions that oppose homosexuality. The incident described by Luanne, where the teacher shared his religious view on homosexuality, is indicative of how educators participate in and give implicit consent to the negative social agreements and societal discourses that can be detrimental to same-gendered families. Educators should be able to work with people from different backgrounds and perspectives, even when such backgrounds and perspectives are experientially, morally and spiritually different from their own.

An active stance advocating respect, tolerance and acceptance of the general conduct of educators and students, as well as actively engaging with these values in the curriculum, might also contribute to creating a safe and caring environment. This might also be a strategy to combat racist factors (such as mentioned by Kashni and Ryland). Educators however need to be informed and trained to recognise assumptions or generalisations about race, sexual orientation, and even gender and social class. In addition, they might benefit from training in ways of discussing these issues with children in an age-appropriate manner.

Bullying has - especially during the past year - become a major factor in our schools and an awareness that children in same-gendered families might also be subjected to harassment, because 
of their family structure, could lead to pro-active behaviours from educators and school management. This could take the form of providing a welcoming and supportive environment for same-gendered families, by offering support groups and counseling, and displaying symbols that welcome and promote diversity; such as posters. In addition, as Jeltova and Fish (2005) note, the school policy can also explicitly specify harassment with regard to gender, race or sexual orientation as being an offence.

Another factor that emerged from the experiences of the children is that the probing or teasing by their peers remained outside the awareness of the educators. Schools have to decide on how they want to handle such incidents. Letting them go by silently might cultivate a culture of discrimination, giving the impression to the perpetrator, bystanders and the victim that the school is not going to act upon such harassment. Explicitly acting will help enforce a zero tolerance attitude.

The incident described by Kashni, of when her mother addressed the class at school, can be seen as an example of how schools can encourage parents to speak at schools or to volunteer in other ways. This links to recommendations based on international research for the holding of open discussions between parents and professionals (Ryan \& Martin, 2000), and even the establishment of gay-straight alliances (Jeltova \& Fish, 2005; Lamme \& Lamme, 2002).

The support that Tom received from friends, who are also growing up in same-gendered families, shows the value of establishing support groups amongst children and even their parents. A strong bond might be fostered where the specific needs of children growing up in same-gendered families can be addressed.

This research leads me to propose that educators in training, and those already in practice, take cognisance of changing family structures in South Africa. Sensitivity is needed with regards to how people construct their lives in different ways. The emphasis should be on creating a safe and caring environment, where diversity is embraced. When the fear of something or someone other is minimised, prejudice, problems associated with domination and discrimination can be addressed. Open and accepting attitudes from educators, school administrators and other families might facilitate the increased well-being and functionality of children in same-gendered families.

Though the above recommendations might seem superficial and uncomplicated, I do acknowledge that oppressions are always focused on and played out in schools. I do not imply that by merely following a few suggested recommendations, people will no longer be subjected to oppression, ridicule and harassment. What we might achieve is the creation of opportunity and a safe space for learners, parents and educators to express themselves, or at least resist the silencing forces by allowing for and expressing their difference.

\section{Conclusion}

The subject of this article was an exploration of reported experiences by children, of how children growing up in same-gendered families negotiate their daily lives in the school context. The stance was taken that schools can be places of discrimination and prejudice - silencing minorities and otherness - such as same-gendered families - or they can be places of openness, tolerance and even acceptance, that serve to encourage disclosure, openness, transparency and authentic relationships 
in schools. As can be constantly perceived, these two standpoints are not definite and exact binaries, but do exist simultaneously in any given school.

Schools are more than mere institutions; they are happenings, practices and processes. Through choice and action, school life and experience can embrace minority groups and celebrate the uniqueness that diversity brings with it. Although - initially - not necessarily easy to understand and manage, accommodating and accepting diversity can be a great educational strength, as it holds the capacity to encourage different values; such as compassion and gentleness.

In-depth research in various school settings is needed, to establish and broaden the current knowledge available on how children growing up in same-gendered families function. This new knowledge may clarify how accommodations and provisions can be made for same-gendered families within the school system, as well as how we can advance society to embrace complex social discourses of diversity.

\section{References}

Alexander, M. (2006). SA legalises gay marriage. [Online]. Available url: http://www.southafrica.info/public_services/citizens/your_rights/same-sex-marriage.htm. Accessed 29 January 2007.

Asher, N. (2007). Made in the (Multicultural) U.S.A.: Unpacking Tensions of Race, Culture, Gender, and Sexuality in Education. Educational Researcher, 36(2), 65-73.

Bernstein, M. \& Reimann, R. (2001). Introduction, in Queer families, queer politics. (pp. 1-17). New York: Columbia University Press.

Bevan, S. \& Bevan, K. (1999). Interviews: meaning in groups, in I. Parker and the Bolton discourse network. Critical textwork, an introduction to varieties of discourse and analysis. (pp. 15-28). Buckingham, Philadelphia: Open University Press.

Bozett, F.W. (1980). How and why gay fathers disclose their homosexuality to their children. Family Relations, 29, 173-179.

Bozett, F.W. (1987). Gay and lesbian parents. New York: Praeger Publishers.

Bozett, F.W. (1989). Gay fathers: A review of the literature. Journal of Homosexuality, 18 (1-2), 137-162.

Cameron-Ellis, J.A. (1999). Church and homosexuality: The relationship between individual religious beliefs, attitudes and the quality of contact. Unpublished master's dissertation. Pretoria: University of Pretoria.

Casper, V., Schultz, S. \& Wickens, E. (1992). Breaking the silences: Lesbians and gay parents and the schools. Teachers College Record, 94(1), 109-137.

Clandinin, D.J. \& Connelly, F.M. (2000). Narrative inquiry, experiences and story in the qualitative research. San Francisco: Jossey-Bass Publishers.

Clarke, Kitzinger \& Potter, J. (2004). 'Kids are just cruel anyway': Lesbian and gay parents' talk about homophobic bullying. British Journal of Social Psychology, 43, 531-550.

Collins, D. (2006). Culture, religion and curriculum: lessons from the 'three books' controversy in Surrey, BC. The Canadian Geographer, 50(3), 342-357.

Costello, C.Y. (1997). Conceiving identity: bisexual, lesbian and gay parents consider their children's sexual orientations. Journal of sociology and social welfare, 24(3): 63-89.

Creswell, J.W. (2002). Educational Research. New Jersey: Merrill Prentice Hall. 
Dundas, S. \& Kaufman, M. (2000). The Toronto lesbian family study. Journal of homosexuality, 40(2): 65-79.

Epstein, D., O'Flynn, S. \& Telford, D. (2002). Innocence and experience: paradoxes in sexuality and education, in D. Richardson \& S. Seidman (Eds). Handbook of lesbian and gay studies. (pp. 271-290).California, London, New Delhi: Sage Publications.

Golombok, S. (1999). Lesbian mother families, in A. Bainham, S. Day Sclater \& M. Richards (Eds). What is a parent? A socio-legal analysis. (pp. 162-180.) Portland: Hart Publishers.

Golombok, S. \& Tasker, F. (1996). Do parents influence the sexual orientation of their children? Developmental psychology, 32(1): 3-11.

Gottman, J.S. (1989). Children of gay and lesbian parents. Marriage and Family Review, 14 (34), 177-196.

Green, R., Mandel, J.B., Hotvedt, M.E., Gray, J. \& Smith, L. (1986). Lesbian mothers and their children: a comparison with solo parent heterosexual mothers and their children. Archives of sexual behaviour, 15(2): 167-184.

Greene, B. (2000). Beyond heterosexism and across the cultural divide, in B. Greene \& G.L. Croom (Eds). Education, research and practice in lesbian, gay, bisexual and transgendered psychology. (pp. 1-45). California, London, New Delhi: Sage Publications.

Hancock, K.A. (2000). Lesbian, gay and bisexual lives, in B. Greene \& G.L. Croom (Eds). Education, research and practice in lesbian, gay, bisexual and transgendered psychology. (pp. 91-130.) California, London, New Delhi: Sage Publications.

Hare, J. (1994). Concerns and issues faced by families headed by a lesbian couple. Families in society, 75(1): 27-35.

Jeltova, I. \& Fish, M.C. (2005). Creating school environments responsive to gay, lesbian, bisexual and transgender families: traditional and systemic approaches for consultation. Journal of Educational and Psychological Consultation, 16(1 \& 2), 17-33.

Knoesen, E. (2003). Speech to OUT AGM 2003. [Online]. Available url: http://www.equality.org.za/archive/2--3/outagm.php. Accessed 19 July 2004.

Knoesen, E. (2004). Queering the vote. Mail \& Guardian, 03 March 2004. p. 15.

Koepke, L., Hare, J. \& Moran, P.B. (1992). Relationship quality in a sample of lesbian couples with children and child-free lesbian couples. Family Relations, 41(2), 224-229.

Kroeger, J. (2006). Stretching performances in education: the impact of gay parenting and activism on identity and school change. Journal of Educational Change, 7, 319-337.

Kumashiro, K. K. (2000). Toward a Theory of Anti-Oppressive Education. Review of Educational Research, 70(1), 25-53.

Kumashiro, K. K. (2001). "Posts" Perspectives on Anti-Oppressive Education in Social Studies, English, Mathematics, and Science Classrooms. Educational Researcher, 30(3), 3-12.

Kumashiro, K. K. (2003). "Queer Ideals in Education." Journal of Homosexuality, 45(2/3/4), 365367.

Kumashiro, K. K. (2004). Uncertain Beginnings: Learning to Teach Paradoxically. Theory Into Practice, 43(2), 111-115.

Lamme, L. L. \& Lamme, L. A. (2001). Welcoming children from gay families into our schools. Educational leadership, January, 65-68.

MacCallum, F. \& Golombok, S. (2004). Children raised in fatherless families from infancy: a followup of children of lesbian and single heterosexual mothers at early adolescence. Journal of child psychology and psychiatry, 45(0): 1-13. 
Mason, J. (2nd ed.). (2002). Qualitative researching. California, London, New Delhi: Sage Publications. Morse, J.M. \& Richards, L. (2002). Read me first for a user's guide to qualitative methods. California, London, New Delhi: Sage Publications.

Paechter, C. (2000). Growing up with a lesbian mother: A theoretical based analysis of personal experience. Sexualities, 3(4), 395-408.

Patterson, C.J. (1992). Children of lesbian and gay parents. Child Development, 63, 1025-1042.

Patterson, C.J. (1997). Children of lesbian and gay parents. Advances in clinical child psychology, 19: 235-282.

Patterson, C.J. (2000). Family relationships of lesbians and gay men. Journal of Marriage and the Family, 62(4), 1052-1069.

Perlesz, A., Brown, R., Lindsay, J., McNair, R., De Vaus, D. \& Pitts, M. (2006). Family in transition: parents, children and grandparents in lesbian families give meaning to "doing family". Journal of Family Therapy, 28, 175-199.

Powers, C. (1998). Lesbian mother wins custody of her child. The Star, 22 April, p. 3.

Ray, V. \& Gregory, R. (2001). School experiences of the children of lesbian and gay parents. Family Matters, 59, 27-35.

Ryan, D. \& Martin, A. (2000). Lesbian, gay, bisexual, and transgender parents in the school systems. School psychology review, 29(2), 207-216.

Singh, D. (1995). Discrimination against lesbians in family law. South African Journal on Human Rights, 11(4), 571-581.

Tasker, F. (1999). Children in lesbian-led families: a review. Clinical child psychology and psychiatry, 4(2): 153-166.

Tasker, F. \& Golombok, S. (1997). Growing up in a lesbian family, effects on child development. New York: The Guilford Press.

Terre Blanche, M. \& Durrheim, K. (Eds). (1999). Research in practice, applied methods for the social sciences. Cape Town: UCT Press.

Underhill, G. (2003). The story of us. Femina, June 2003. p. 72-75.

Vanfraussen, K., Ponjaert-Kristoffersen, I. \& Brewaeys, A. (2002). What does it mean for youngsters to grow up in a lesbian family created by means of donor insemination? Journal of Reproductive and Infant Psychology, 20(4), 237-252.

Van Voorhis, R. \& McClain, L. (1996). Accepting a lesbian mother. Journal of contemporary human services, 78(6): 642-650.

Victor, S.B. \& Fish, M.C. (1995). Lesbian mother and the children: A review for school psychologists. School Psychology Review, 24(3), 456-479.

Wallis, C. (2003). A house divided. Time Magazine, 18 August, p. 44-45.

Wind, L.H. (1999). Developmental identity crisis in non-traditional families, in N.B. Webb (Ed.). Play therapy with children in crisis. New York: The Guildford Press. pp. 318-338.

Wright, J.M. (2001). Aside from one little, tiny detail, we are so incredibly normal: Perspectives of children in lesbian step families, in M. Bernstein \& R. Reimann (Eds). Queer families, queer politics. (pp. 272-290). New York: Columbia University Press.

Ziehl, S. C. (2001). Documenting changing family patterns in South Africa: are census data of any value? African sociological review, 5(2), 36-62. 


\section{Carien Lubbe, PhD}

Department of Educational Psychology,

Faculty of Education

Groenkloof campus

All Purpose Building, C114

University of Pretoria

Republic of South Africa

0001

Telephone: +27 124202765

E-mail: carien.lubbe@up.ac.za 